\title{
Distracted by details: Narrative influence following conflicting stories
}

\author{
Joseph J.P. Simons \\ Melanie C. Green \\ University of North Carolina, Chapel Hill
}

Work on narrative influence has demonstrated that stories can have a strong effect on people's thoughts and attitudes. However, existing research has not addressed how people respond to multiple stories endorsing different conclusions. The current studies examined how reading two conflicting narratives influences people's decisions about a subsequent situation, with particular emphasis on how resemblances between the narratives and the situation moderate the effects. Across two studies, participants read two testimonials which described the successful use of different treatments for a medical disorder, and then made treatment recommendations for a patient who resembled one of the testimonials in treatment-relevant ways. The key manipulation was whether the patient also resembled the other testimonial in treatment-irrelevant ways. Both studies found that these distracting, irrelevant similarities led to less appropriate treatment recommendations. The effect on decision confidence, however, was less clear, with some suggestion of both an increase (Study 1) and a decrease (Study 2) in confidence.

People live their lives surrounded by stories; narratives are a pervasive feature of face-to-face conversations, mass media, and online communication. Recent experimental work has established that these stories can have a strong impact on our beliefs (e.g., Appel \& Richter, 2010; Green \& Brock, 2000; Mazzocco, Green, Sasota \& Jones, 2010; Strange \& Leung, 1999) through mechanisms distinct from other forms of persuasion (Green \& Brock, 2000), and may be especially effective at bypassing people's critical faculties (e.g., Dal Cin, Zanna \& Fong, 2004; Moyer-Gusé \& Nabi, 2010). However, existing studies of narrative persuasion have tended to examine the effect of single, isolated narratives, neglecting the fact that people will often have heard a number of conflicting stories which point to very different conclusions. The current research addresses the question of how narrative influence functions given this multiplicity of stories.

The abundance of narratives is particularly worrisome with regard to health issues. Blogs, social networks, and user-modifiable websites provide unprecedented opportunities for patients and caregivers to contribute their perspectives on medical topics (e.g., The Economist, 2007). Indeed, a recent study suggested that $34 \%$ of all Internet users have read someone else's commentary or experience on health or medical topics (Fox, 2011). These technological innovations, combined with medical information sites such as WebMD, are leading patients to become increasingly independent from healthcare professionals, seeking out information and making medical decisions themselves (Eysenbach, 2008; Herrick, 2005). However, patients are making these decisions

This is an Accepted Manuscript of an article published by Taylor \& Francis in Media Psychology on 30 May 2013, available online: http://www.tandfonline.com/doi/full/10.1080/15213269.2013.784694. 
against the backdrop of numerous, often conflicting, stories. It is important to consider whether this plethora of contradictory advice is detracting from the beneficial impact of health testimonials.

The current research focuses on the effects of conflicting narratives, as opposed to other forms of communication (such as more direct persuasive messages). In addition to theoretical goal of furthering understanding of narrative persuasion, this focus is also motivated by pragmatic considerations. The recounting of personal stories may have benefits for the teller as well as the audience (McLean, Pasupathi \& Pals, 2007). Thus, within a health context, while patients can provide other informational resources (factual information, the contact details for professionals, emotional support), narratives are likely to remain a major aspect of online information sharing. Furthermore, because narratives are not so explicitly persuasive as other forms of communication, they may lead to reduced critical scrutiny from readers (Green \& Brock, 2000; Moyer-Gusé \& Nabi, 2010). As such, understanding the impact of narratives is central to understanding the impact of online health information.

\section{The importance of resemblances}

Our approach to understanding the impact of conflicting narratives stems from the premise that one factor determining how much a narrative influences a subsequent decision is the extent to which the narrative resembles the decision case. Imagine John reads a testimonial in favor of Treatment A. He then has to make a decision about treating a future case (which we will subsequently refer to as the judgment case).
Our starting point is that the more similar the judgment case is to the testimonial, the more John will think that Treatment A is a good option. This premise is consistent with the idea that narratives serve as guides or templates for interpreting new situations (e.g., Mazzocco, Green \& Brock, 2007; Schank \& Berman, 2002).

This approach suggests the novel prediction that hearing two or more conflicting narratives should not be problematic if the judgment case only resembles one of these narratives. In contrast, when the judgment case resembles both narratives, there may be cognitive difficulties, as it is unclear which narrative should guide decision making.

This resemblance-based approach to conflicting narrative influence foregrounds the distinction between relevant and irrelevant similarities. Given a person's background knowledge about a domain, some kinds of similarity between a new case and a prior narrative will be an appropriate basis for decisions (relevant similarities), whereas other similarities will be less appropriate (irrelevant similarities). With medical examples, points of similarity such as age, level of physical health, and medical history might be important in determining whether a testimonial is an appropriate guide, because background cultural knowledge dictates that these factors can often affect the efficacy of a given treatment. On the other hand, factors such as hair color and taste in music are typically much less relevant.

For example, imagine John has two friends who had a particular medical condition. Amy (who is generally healthy) has told him about her great 
experiences with Treatment A, whereas Brenda (who loves classical music) talks about how fantastic Treatment B is. John then has to decide if Treatment A or B is better for Susan (who is both healthy and a classical music fan). We would find it rather odd (to say the least) if John were to argue that Susan should take Treatment $B$ because of the love of classical music she shares with Brenda. To put this example in our terms, Susan resembles both Amy and Brenda, but the resemblance to Amy is relevant and the resemblance to Brenda is irrelevant. Hence, Treatment A seems a more appropriate suggestion.

It is worth noting that the terms 'relevant', 'irrelevant' and 'appropriate' are relative to a person's knowledge of the domain in question. A 'relevant' point of similarity is one which, given general background knowledge, is the kind of factor which should determine what is a good decision. Similarly, the 'appropriate' course of action is one which is pointed to by relevant factors. Thus, while these terms are normative in the sense of implying consistency with a broader knowledge base, they are not meant to imply a timeless or unchanging truth about the decision. It is for this reason we refer to 'appropriate' rather than 'correct' decisions.

In the case of multiple conflicting narratives, a key question is how good people are at recognizing the relevance of resemblances. If people are good at discounting irrelevant similarities, multiple narratives will be less of a hindrance to effective decision making. Even when the judgment case resembles a number of prior narratives, people will be able to discount the irrelevant similarities, and so decide on the basis of relevant factors. If people tend to give similar weight to relevant and irrelevant similarities, however, conflicting narratives pose a unique challenge to effective decision making. Even if the case at hand shares important similarities with a prior narrative, irrelevant similarities to a conflicting narrative could lead to confusion and ambivalence between the two options. The irrelevant similarities could prove a distraction from the more relevant resemblances.

At this stage, it is worth noting some boundary conditions for these processes. First, in actual decision contexts, one successful exemplar may not be enough for an individual to consider that treatment to be the most appropriate. Second, other features of narratives and decision context will also impact the decisions people make. For example, stories can be more or less involving (e.g., Green \& Brock, 2000), different decision options may be attractive for reasons beyond similarity (e.g., people may have a pre-existing preference for one option), and people may have different knowledge about the domain in question (e.g., doctors and their patient's family). Relatedly, we are using the term 'relevance' to mean similarity between testimonial and judgment case, whereas there may be other forms of relevance in actual decision contexts (e.g., ego-involvement). In the interests of providing a pure test of our hypotheses, participants only read one exemplar for each treatment, and we only explicitly model a small number of factors as influencing participants' responses. While this approach is simplified somewhat from actual decision contexts, it also allows for a strong test of the hypothesized processes and causal relationships. 


\section{The current research}

In our studies, participants made a medical decision for a fictional patient after reading two prior testimonials. These testimonials were supposedly written by people (Sean Bryant and Philip Alexander) who had successfully been treated for the same fictional medical disorder (enthropic lysestrial disorder, or ELD), but with different treatments. The patient (Chris Russell) always resembled the author of one of the prior testimonials in ways which were relevant for the treatment decision (meaning one of the treatments was a more appropriate choice). However, in some cases, Chris also had irrelevant, distracting similarities to the author of the other testimonial. The research question is whether these distracting similarities interfere with participants' decisions for Chris.

Given that in other domains, people are poor at distinguishing relevant and irrelevant information (e.g., the dilution effect, Kemmelmeier, 2004; the representativeness heuristic, Tversky \& Kahneman, 1974), we hypothesize that people will indeed generally be distracted by irrelevant similarities. Specifically, we hypothesize that irrelevant similarities will lead to two consequences. First, participants will make less appropriate decisions; the lack of clarity about which template to apply will lead to a reduced preference for the more appropriate treatment (H1). Second, participants should show reduced confidence; participants will be less certain of the recommendations they ultimately make (H2).

One noteworthy feature of our design is that each testimonial plays different roles in different conditions. In some conditions, the target patient resembles Sean in relevant ways and may additionally resemble Philip in irrelevant ways. In other conditions, the roles are reversed, and the patient resembles Philip in relevant ways and may also resemble Sean in irrelevant ways. This feature of the design makes explanations of our results in terms of features specific to either testimonial, treatment, or set of similarities implausible. A design challenge for this research is that it is hard to provide meaningfully different testimonials and decision options while not introducing confounding factors (e.g., different treatments entailing different risks). If each testimonial was only used in one role (e.g., if Sean's testimonial was always relevant), then it any effects found may be due to specifics of the testimonials used. However, by using each narrative in both the relevant and irrelevant roles, we can bypass this problem.

\section{Study 1}

This study tested whether distracting details lead to both less appropriate treatment recommendations $(\mathrm{H} 1)$ and reduced decision confidence $(\mathrm{H} 2)$.

\section{Method}

Design. The study had a 2 (Decision relevant similarities: Sean vs. Philip) x 2 (Distracting similarities: Present vs. absent) design. ${ }^{1}$

\footnotetext{
1 We originally included conditions in which the judgment case only resembled one of the testimonials in decision-irrelevant ways. These conditions did not show interpretable effects and so were dropped from the analysis.
} 
Participants. Participants were 111 undergraduates (78 female, 30 male, 3 unspecified), who completed the study in exchange for course credit. Two participants had substantial missing data (including all the DVs), and hence could not be included.

\section{Materials.}

Medical briefing. The fictional medical disorder (ELD) was introduced as a liver problem, with initially mild symptoms building to more serious consequences. Two drug treatments were introduced: corticosteroids (CS) were described as a palliative which would safely slow the progression of the disorder, whereas anthoral amphates (AA) were described as a more risky cure, which would treat the underlying problem but necessitated a hospital stay and risked a major negative reaction. In a pilot test, participants were equally likely to pick either of these treatments to undergo themselves; of 23 participants, 11 chose CS and 12 chose $\mathrm{AA}, \chi^{2}(1, \mathrm{~N}=23)=.04, p=.84$.

Testimonials. The two testimonials described the experiences of fictional ELD patients, each of whom was successfully treated with a different drug. Both authors (Sean Bryant and Philip Alexander) were described as 29 year old Caucasian males, and recounted similar stories about initially shrugging off mild symptoms (Sean, "just mild stomach pains, nothing you would really notice"; Philip, "just regular pains that could be caused by a million minor things") before more drastic manifestations (Sean, "like someone had kicked me right in the gut"; Philip, "so much worse than anything I had felt before") forced them to seek medical help. Both described struggling emotionally with their diagnosis (Sean, "everything just seemed kind of grey"; Philip, "it really makes you realize you are not immortal"). Both received successful treatment, Sean with the corticosteroids and Philip with the anthoral amphates. Both were happy with the treatment they received (Sean, "I feel really lucky to have come out of it so well"; Philip, "going through it has really made me appreciate normality"). Importantly, each author mentioned two features of their situation which were decision-relevant (Sean was diagnosed early, and had an insecure job; Philip had good general health, and a close friendship network to provide support during recovery), and two decision-irrelevant features of themselves (Sean worked for the government and liked classical music; Philip was a fan of baseball and had blond hair and blue eyes). The decision-relevant features were explicitly linked to the success of the treatment by the testimonial authors (e.g., social support was cited as an important factor in helping recover from the anthoral amphates). Furthermore, in a pilot test, participants rated the relevance of these features to medical decisions in general. The decision-relevant features $(M=5.43, S D=0.99)$ were rated significantly higher than the irrelevant features $(M=1.93, S D=1.03), t(9)=11.39, p<.001$.

Self-choice task. To reduce any effects of using one's own medical preferences rather than the information about target patient as a basis for the decision, participants were given an opportunity to express which treatment they would prefer to undergo themselves followed by ratings of confidence and ease of the decision (on 7-point scales). These responses were not analyzed, and were included merely to reduce the effect of personal preferences on subsequent responses. 
Judgment case. The judgment case was similar to the testimonials; the author (Chris Russell, a 28-year old Caucasian male) progressed through mild symptoms ("just some mild on-and-off pains") to a more severe outbreak ("so bad it even made me vomit pretty often"). However, this narrative ended with Chris facing the decision between the two treatments ("I'm really not sure which one is going to be best for me"). Importantly, the narrative was constructed such that similarity to the testimonial authors could be manipulated by including any of the four sets of features (i.e., Sean relevant, Sean irrelevant, Philip relevant, Philip irrelevant) from the prior testimonials. See the top section of Table 1 for a summary of which details were embedded in each condition.

Treatment recommendations and confidence. Participants completed two measures assessing which treatment they thought was a better option for Chris. First, they independently rated how appropriate CS and AA would be as treatments for Chris (treatment endorsements, rated on 7-point scales running from do not agree to strongly agree). Hence a participant might think that CS were a good option for Chris and rate them at 6 , but AA were a poor choice and so rate them at a 2. Second, participants made a forced choice of which

Table 1.

Details added to the judgment case to manipulate resemblance to the testimonial authors

\begin{tabular}{|c|c|c|}
\hline & $\begin{array}{l}\text { Relevant similarity: Sean } \\
\text { (Appropriate treatment: } \\
\text { Corticosteroids) }\end{array}$ & $\begin{array}{l}\text { Relevant similarity: Philip } \\
\text { (Appropriate treatment: } \\
\text { Anthoral amphates) }\end{array}$ \\
\hline \multicolumn{3}{|c|}{ Study 1} \\
\hline \multirow{2}{*}{$\begin{array}{l}\text { No distracting } \\
\text { resemblances }\end{array}$} & Early diagnosis & Good health \\
\hline & Job insecurity & Close friendship network \\
\hline \multirow{4}{*}{$\begin{array}{l}\text { Distracting irrelevant } \\
\text { resemblances }\end{array}$} & Early diagnosis & Good health \\
\hline & Job insecurity & Close friendship network \\
\hline & Baseball fan & Classical music fan \\
\hline & Blond hair and blue eyes & Works for local government \\
\hline \multicolumn{3}{|c|}{ Study 2} \\
\hline \multirow{4}{*}{$\begin{array}{l}\text { Supporting irrelevant } \\
\text { resemblances }\end{array}$} & Early diagnosis & Good health \\
\hline & Job insecurity & Close friendship network \\
\hline & Classical music fan & Baseball fan \\
\hline & Works for local government & Blond hair and blue eyes \\
\hline \multirow{4}{*}{$\begin{array}{l}\text { Distracting irrelevant } \\
\text { resemblances }\end{array}$} & Early diagnosis & Good health \\
\hline & Job insecurity & Close friendship network \\
\hline & Baseball fan & Classical music fan \\
\hline & Blond hair and blue eyes & Works for local government \\
\hline
\end{tabular}


treatment was most appropriate for Chris (the treatment decision, a dichotomous variable). Furthermore, they also indicated how confident they were in each of these three ratings (the confidence measures, rated on 7-point scales). Hence, a participant who was very confident in their recommendations might respond with a 6 for all three ratings.

Need for cognition. Need for cognition measures individuals' dispositional enjoyment of thinking and willingness to engage in effortful cognitive activity. It has been linked to greater elaboration of messages and hence stronger attitudes (e.g., Haugtvedt \& Petty, 1992), and therefore may be a positive predictor of confidence in the current study. That is, high need for cognition participants may invest more thought in the decision (or at least perceive themselves to have done so; Barden \& Petty, 2008), and hence be more firm in their decisions. This effect is not a central prediction of the study, but does represent a potential additional source of variance in responses which may reduce power. To allow us to control for this additional source of variance, participants completed the 18-item need for cognition scale (Cacioppo, Petty \& Kao, 1984).

Procedure. The study, presented as an investigation of medical decisions, was conducted online using the Surveymonkey website. Participants who signed up as part of the Psychology Participant Pool were sent a link to the study, and were able to complete it on their own computers at their convenience. After the initial medical briefing, participants read the two testimonials (order was counterbalanced across participants) and completed the selfchoice task (to reduce the effects of personal preference). Finally, they read the judgment case and completed the treatment recommendations and decision confidence measures, the need for cognition scale, and demographic items. ${ }^{2}$

\section{Results}

\section{Treatment recommendations: Did distracting similarities lead to worse choices?}

Prior to analysis, the two continuous treatment endorsements and the dichotomous treatment decision were re-coded in terms of appropriate and inappropriate treatments. That is, rather than analyzing these variables in terms of whether participants recommended $\mathrm{CS}$ or AA, we analyzed them in terms of whether participants recommended the appropriate (matched to relevant similarities) or inappropriate treatment.

As the continuous treatment endorsements were negatively correlated $(r=-.48, p<.001)$, these variables were analyzed using a 2 (Relevant similarities: Sean vs. Philip) x 2 (Distracting irrelevant similarities: Absent vs. present) $\mathrm{x} 2$ (Treatment: Appropriate vs. inappropriate) ANOVA with repeated measures on the final factor. ${ }^{3}$ This analysis revealed the predicted

\footnotetext{
${ }^{2}$ Several other measures were collected but will not be reported here. Participants completed measures assessing transportation (Green \& Brock, 2000) into the medical outline and each testimonial, perceived self-similarity to the authors, ease ratings of the forced choice, and attributional complexity (Fletcher, Danilovics, Fernandez, Peterson, \& Reeder, 1986).

3 Across analyses, we do not discuss effects which were irrelevant to our main hypotheses (e.g., moderating effects of relevant similarity type, indicating different effects when the appropriate treatment was CS vs. AA). As these effects do not substantively affect the patterns reported here, they will not be discussed further. Details are available from the first author on request.
} 


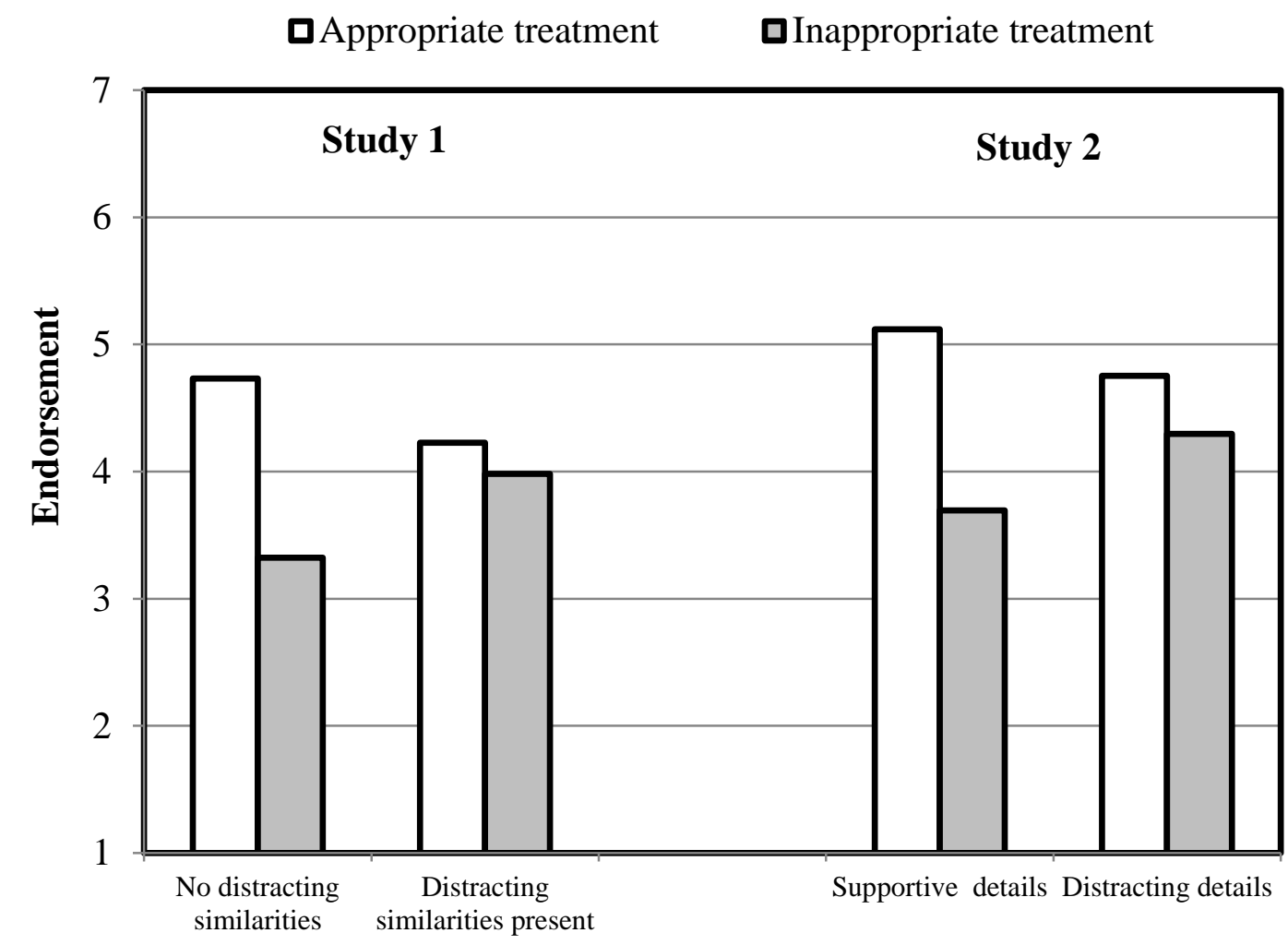

Figure 1. Recommendation of appropriate and inappropriate treatments in the presence of distracting similarities.

interaction between the presence of irrelevant similarities and treatment type, $F(1,105)=4.56$, $p=.04, \eta_{p}^{2}=.04$. The means from this interaction are plotted in Figure 1. When there were no distracting similarities, there was a clear preference for the appropriate treatment, $F(1,54)=18.76, p<.001, \eta_{p}^{2}=.26$. When there were distracting similarities, however, this preference was eliminated, $F(1,51)=0.31, p=$ $.58, \eta_{p}^{2}=.01$. These results supported $\mathrm{H} 1$.

The dichotomous treatment decision was analyzed using logistic regression. The probability of choosing the appropriate treatment was predicted from the relevant similarities (Sean vs. Philip), the distracting similarities (absent vs. present), and the interaction of these two factors. While distracting similarities did reduce the probability of choosing the appropriate treatment, this effect was not significant, $B=-0.64, p=.26$.

\section{Confidence ratings: Did distracting similarities undermine confidence?}

The three confidence ratings (confidence in the endorsement of the appropriate treatment, the endorsement of the inappropriate treatment, and the treatment decision) were highly correlated ( $r \mathrm{~s}>.62, p \mathrm{~s}<.001)$. To allow for these intercorrelations, these variables were analyzed with a 2 (Relevant similarities: Sean vs. Philip) x 2 (Distracting irrelevant similarities: Absent vs. present) x 3 (Confidence ratings: Appropriate vs. inappropriate vs. forced choice) ANOVA, with repeated measures on the final 
factor. Across all three ratings, means were higher when distracting similarities were present $(M \mathrm{~s}=4.45,4.74,4.60 ; S D \mathrm{~s}=1.59,1.56,1.55$ for the appropriate, inappropriate and forced choice ratings respectively) than when they were absent $(M \mathrm{~s}=4.35,4.16,4.20 ; S D \mathrm{~s}=1.55$, $1.61,1.53$ in the same order). This effect was non-significant, $F(1,104)=2.05, p=.16, \eta_{p}^{2}=$ .02 , but controlling for need for cognition $(\alpha=$ .89 , mean-centered because the analysis was within-subjects) brought the effect to marginal significance, $F(1,94)=2.94, p=.09, \eta_{p}^{2}=.03$. These results did not support $\mathrm{H} 2$, and indeed, showed a non-significant trend in the opposite direction (irrelevant similarities showed some evidence of increasing participants' confidence in their recommendations).

\section{Discussion}

As predicted, distracting similarities led to less appropriate treatment recommendations. When there were only decision-relevant similarities to one of the testimonials, participants showed a clear preference for that testimonial's treatment. Decision-irrelevant similarities to the other narrative, however, eliminated this preference. The results from the forced choice also showed this pattern but did not reach significance, which may be due to a lack of granularity in this measure.

Confidence in these recommendations, however, showed unexpected results. Rather than the predicted decrease in confidence, distracting similarities were associated with a marginally significant increase in confidence. This result could simply be random fluctuation. On the other hand, distracting details could make the decision more difficult, and as such may have prompted more thought by participants. This thought may have been biased (given that participants did not endorse the appropriate treatment any more than the inappropriate one), but may have increased participants' attitude strength (Barden \& Petty, 2008).

Although the results of this study were promising, our manipulation of similarity had some potential problems. First, presence of distracters was conflated with number of similarities. In the relevant-similarities-only condition, there were only two points of similarity between the target and testimonials, whereas in the distracting details condition there were four (two relevant, two irrelevant). Second, in the relevant-similarities-only condition, one of the testimonials was unrelated to the task (as the judgment case was not manipulated to have relevant or irrelevant similarities to that testimonial). Giving participants this unusable stimulus breaks the conversational norm of only telling people relevant information (Grice, 1989), and hence may have confused participants. That is, even if participants could not see how this testimonial related to the task, they may have assumed that the experimenters provided this information because it was intended to be useful in some way.

\section{Study 2}

The second study aimed to replicate and extend the findings of Study 1. A number of changes were made to the procedure. First, the study was conducted in the laboratory rather than online. Second, the similarity manipulation was revised to remove the confound between similarity and amount of information. Third, to reduce 
concerns about conversational norms, we emphasized that the testimonials were randomly selected (by adding an animated loading bar while the computer supposedly randomly chose a testimonial). By emphasizing the (supposedly) random selection of the narratives, we undermined the idea that each narrative would necessarily be relevant to the decision; the computer may have randomly selected an irrelevant testimonial. Finally, to clarify the prior findings on decision confidence, a number of measures of amount of thought and final attitude strength were included. If the nonsignificant increase in confidence found in Study 1 is a genuine effect, it should be detectable using more extensive attitude strength measures, and should be accompanied by a greater amount of thought about the decision (both in terms of quantity and breadth of thinking).

\section{Method}

Design. The study used a 2 (Relevant similarities: Sean vs. Philip) x 2 (Irrelevant similarities: Supporting vs. distracting) x 2 (Order of DVs: Thought process vs. outcomes first) between-subjects design. Unless mentioned below, all DVs were analyzed using an ANOVA following this design. The order of DVs was varied because completing the thought process measures first may artificially increase thought about the decision, and thus could change treatment recommendations and confidence. The order of testimonial presentation was counterbalanced across participants.
Participants. Participants were 116 undergraduate students (60 female, 56 male) who participated for course credit.

\section{Materials.}

Medical briefing and testimonials. The briefing and testimonials were very similar to those used in Study 1. Minor changes were made to improve readability, and a sentence asserting that the risks of anthoral amphates were linked to general level of health was eliminated (to ensure that it was not providing an independent basis for decisions). To emphasize that the testimonials were randomly chosen, a loading animation was added before each one (supposedly while the computer selected a testimonial).

Treatment case. The judgment case was the same as in Study 1, but a different similarity manipulation was used. There were always four points of similarity between the treatment case and the prior testimonials (two relevant, two irrelevant). We independently manipulated whether the judgment case resembled Sean or Philip in decision-relevant ways, and whether the irrelevant similarities were drawn from the same testimonial or from the conflicting testimonial. Thus, in this procedure, the key manipulation was whether the irrelevant similarities supported or distracted from the relevant similarities, rather than whether they were present or not. These manipulations are summarized in the bottom section of Table 1 .

\section{Thought process variables:}

Amount and breadth of thought. Several measures of the amount and breadth of thought were collected. First, participants completed a 
thought listing task and subsequently rated whether each thought suggested CS or AA would be the better treatment for Chris (thought valence, rated using a 7-point scale ranging from strongly suggests CORTICOSTEROIDS would be the best treatment through no implications either way to strongly suggests ANTHORAL AMPHATES would be the best treatment). The number of thoughts generated indicated the amount of thought, whereas the standard deviation of valence ratings indicated breadth of thought. Second, participants completed a 5-item measure of perceived processing of the information (rated on a 7-point scale, adapted from Barden \& Petty, 2008; e.g., to what extent did you think a lot about the information about Chris Russell's decision?).

\section{Outcome variables:}

Treatment recommendations and attitude certainty. Participants' recommendation of treatment for Chris was measured using the same measures as in Study 1 (i.e., individual treatment endorsements and a decision between the two treatments). Confidence in these recommendations was measured with a 7-item scale of attitude certainty (measured on 9-point scales, adapted from Petrocelli, Tomala \& Rucker, 2007), which included subscales of attitude clarity (e.g., how certain are you that you really know what your true opinion on this topic is?) and attitude correctness (e.g., how certain are you that the opinion you have towards Chris' treatment is the correct opinion to have?), and a scale of issue-specific defensive confidence (rated on 5-point scales, adapted from Albarracín \& Mitchell, 2004; e.g., if I had to discuss this issue, I could successfully defend my ideas). A higher score represented a greater level of certainty and confidence; the defensive confidence items were anchored with not at all characteristic of me and extremely characteristic of me, whereas the anchors for the certainty scales varied across items.

Procedure. Participants completed the study on laboratory computers. They were first presented with the medical briefing, two testimonials, and

Table 2.

Means and standard deviations for effect of distracting vs. supportive similarities on breadth of thought and decision confidence in Study 2

\section{Decision confidence}

\section{Thought}

variability

$\begin{array}{ccc}\text { Attitude } & \text { Attitude } & \text { Defensive } \\ \text { clarity } & \text { correctness } & \text { confidence }\end{array}$

\begin{tabular}{lcccc}
\hline Distracting & 1.41 & 5.84 & 4.60 & 3.31 \\
& $(0.86)$ & $(1.81)$ & $(1.64)$ & $(0.62)$ \\
Supporting & 1.13 & 6.42 & 5.10 & 3.54 \\
& $(0.84)$ & $(1.77)$ & $(1.77)$ & $(0.71)$ \\
\hline
\end{tabular}

N.B. Standard deviations in parentheses. Attitude clarity and correctness are subscales of an attitude certainty measure. 
self-choice task. They then read the treatment case and completed the thought process and outcome measures. The order of these blocks of measures was varied between subjects. Finally, participants completed the need for cognition scale and demographic items. ${ }^{4}$

\section{Results}

Analytic strategy. All DVs were analyzed using a three-way ANOVA to assess the effects of relevant similarities (Sean vs. Philip), irrelevant similarities (Supporting vs. distracting) and order of DVs (Thought process vs. outcomes first). Additional within-subjects factors were added to specific analyses to allow for inter-correlations between conceptually related variables (endorsement of the two treatments, different measures of decision confidence).

\section{Treatment recommendations: Did distracting similarities lead to worse choices?}

The endorsement ratings for the appropriate and inappropriate treatments are shown in Figure 1. As in Study 1, these two variables showed a substantial negative correlation, $(r=-.73, p<$

\footnotetext{
4 As in Study 1, participants also completed measures of transportation into each testimonial (but not the medical outline) and attributional complexity. In addition, participants completed measure of potential and subjective ambivalence (Priester \& Petty, 1996). These were intended as measures of thought variety and decision confidence respectively, and hence were completed in the thought process and outcomes sections. The means of these variables were in the predicted direction (i.e., ambivalence of both kinds was higher following distracting irrelevant similarities, supporting the findings in the other variables). However, these effects failed to reach significance, $F_{\mathrm{s}}(1,108)<2.32, p \mathrm{~s}>.13, \eta_{p}^{2} \mathrm{~s}<.03$, and so will not be discussed in more detail.
}

.001) and so were analyzed by adding a withinsubjects factor of treatment (appropriate vs. inappropriate) to the basic ANOVA design. Consistent with $\mathrm{H} 1$, there was a significant preference for the appropriate treatment when the irrelevant similarities were supportive, $F(1$, $55)=11.60, p<.01, \eta_{p}^{2}=.17$, but no preference when the irrelevant similarities were distracting, $F(1,53)=2.24, p=.14, \eta_{p}^{2}=.04$. This interaction between distracting similarities and the treatment type was marginally significant, $F(1,108)=2.74, p=.10, \eta_{p}^{2}=.03 .^{5}$ Thus, these results replicated Study 1 and supported $\mathrm{H} 1$.

The decision between treatments was analyzed using logistic regression. The probability of participants choosing the appropriate treatment was predicted from relevant similarity type, irrelevant similarity type, response order, and their interactions. As in the first study, distracting similarities did not have a significant

\footnotetext{
${ }^{5}$ Removing a single potential outlier (identified on the basis of a high Cook's distance, indicating disproportionate influence on the final outcome; Cohen, Cohen, West \& Aiken, 2003) was sufficient to bring this interaction to significance, $F(1,107)=3.91, p=.05, \eta_{p}^{2}=$ .04 . The same outlier detection procedure was used in all other analyses, but did not affect the results substantially. In Study 1, no analysis showed outliers. In Study 2, in addition to the case mentioned above, removing one highly influential observation from the analysis of thought variability bought the interaction between response order and presence of irrelevant similarities to significance, $F$ $(1,93)=4.04, p=.05, \eta_{p}^{2}=.04$, with the effect of irrelevant similarities being eliminated when the participants completed the outcome measures first, $F(1$, 50) $<.001, p>.99, \eta_{p}^{2}<.001$. Furthermore, eliminating a single highly influential case from the analysis of attitude strength led to the main effect of irrelevant similarities being significant both with and without need for cognition as a control, $F \mathrm{~s}(1,107 / 106)>4.80$, ps $<.04, \eta_{p}^{2} \mathrm{~s}>.04$.
} 
effect on the rate with which the appropriate treatment was chosen, $B=-0.13, p=.85$.

\section{Amount of thought about the decision: Did distracting similarities lead to more thought?}

Number of thoughts generated did not show a main or interactive effect of irrelevant similarity type, $F_{\mathrm{s}}(1,108)<0.60, p \mathrm{~s}>.44, \eta_{p}^{2} \mathrm{~s}<.01$, nor did perceived processing of the information, $\alpha=$ $.88, F \mathrm{~s}(1,108)<1.76, p \mathrm{~s}>.18, \eta_{p}^{2} \mathrm{~s}<.02$.

\section{Breadth of thought about the decision: Did distracting similarities lead to wider thinking?}

The standard deviation of thought valence ratings for each participant showed a significant main effect of distracting similarities, $F(1,94)=$ $5.31, p=.02, \eta_{p}^{2}=.05$. Means are given in Table 2. As can be seen, on average, participants showed broader thought following distracting similarities.

\section{Attitude strength: Did distracting similarities undermine decision confidence?}

The two sub-scales of attitude certainty (clarity, $\alpha=.91$; correctness, $\alpha=.82$ ) and defensive confidence $(\alpha=.88)$ showed a high level of inter-correlation $(r s>.42)$, so were analyzed simultaneously by adding a within-subject factor of confidence measure (clarity vs. correctness vs. defensive confidence) to the basic ANOVA design. Means are given in Table 2. As the dependent variables were measured using different scales, the scores were standardized using a z-transformation. All three responses were higher when the irrelevant similarities were supportive (relative to distracting). This between-subjects effect was significant, $F(1,108)=3.96, p=.05, \eta_{p}^{2}=.04$. Controlling for mean-centered need for cognition reduced the effect to marginal significance, $F(1,107)=3.41, p=.07, \eta_{p}^{2}=.03$. Thus, on balance, these results supported $\mathrm{H} 2$. However, this effect does seem to be somewhat weaker than the others, and as such was just on the edge of significance in the current analyses.

\section{Discussion}

The current study replicated the effects of distracting similarities on treatment recommendations found in Study 1. As before, participants showed a clear preference for the appropriate treatment in the absence of distracting similarities, but endorsed the two options equally when distracting similarities were present. Once again, the forced choice measure showed the same pattern, but the results were far from significance. Again, this is consistent with the idea that the null results were due to a lack of granularity in the measure.

Furthermore, the current study provided greater insight into participants' thought processes. There was no evidence that distracting similarities impacted the amount of thought. However, there was good evidence that distracting similarities led to participants having a broader range of thoughts.

In this study, the effects of distracting similarities on decision confidence supported our initial predictions (H2); distracting similarities lead to reduced attitude certainty. This finding was not entirely robust: controlling for need for cognition reduced the effect to marginal significance. However, the evidence 
for a decrease in confidence was, if anything, stronger than the evidence for an increase in Study 1.

\section{General Discussion}

The findings from these two studies provide strong support for our resemblance-based approach to conflicting narratives. Distracting similarities eliminated the preference for the most appropriate treatment, as well as leading to more diverse thoughts. This finding has strong implications for the use of narratives in health persuasion. Narratives are valuable because they humanize complex information: stories of medical treatments can be less threatening, provide vicarious social support, and illuminate the emotional aspects of a decision (e.g., Kreuter et al., 2007). However, as Winterbottom, Bekker, Conner and Mooney (2008) argue, the lack of research on mechanisms of narrative influence leaves a question mark over their usefulness in promoting good decisions. Our model draws attention to one particular way in which an abundance of narrative may harm decision making; the very details that bring each story to life may also obscure the relevant elements of the template the story provides.

These findings also highlight potential links with other aspects of narrative processing. For example, rich detail may make stories more transporting, and similarities may lead to higher levels of transportation or identification (e.g., Green, 2004). More transporting stories may prove to be more potent distracters; similarly, stories that have characters with which a reader can identify - even if the identification is based on similarities unrelated to the decision - may show heightened decision disruption effects.

The evidence for reduced confidence was more mixed. Study 2 showed the predicted effects; participants were less confident when confronted with distracting similarities. However, Study 1 found some evidence for the opposite effect. This discrepancy could be due to methodological changes between the studies. Nonetheless, it seems that any reduction in confidence is a subtler, less robust effect than the worse decisions. This is surprising, but also serves to underline the danger of conflicting narratives; although unimportant similarities can lead to worse decisions, at least in some cases these decisions may not be made with substantially less confidence.

One question which may be raised is whether this distraction effect is specific to narratives, or whether it could be found with other forms of persuasive messages. Our view is that, while the same effects may be found with other message formats, narratives have two features which make them the best exemplars for these effects: they are specific, and they are detail-rich. First, the effects identified in this paper turn on the idea of resemblance between persuasive message and judgment case. In the current data, for a message to be influential, it has to resemble the judgment case. It is clear how a narrative can resemble a judgment case; both describe individual cases, between which there may be a number of parallels. It is less clear how other forms of persuasive messages (such as statistical arguments, addressing broad trends rather than specific individuals) can resemble a particular judgment case. Second, by their very nature, narratives are more likely to contain 
irrelevant or peripheral detail. Stories use tangential details as a way of building the narrative world and drawing in the listener. In other forms of argumentation, however, details irrelevant to the main point are less likely to be included. As such, while it may well be possible to see distraction (or at least analogous) effects with other types of persuasive messages, narratives seem a particularly fertile medium for these phenomena.

A second question is the causal mechanism behind these effects. Our findings are consistent with the idea that the persuasive effect of narratives is, at least in part, due to their role in shaping interpretation of future experiences. When people encounter new events, they may use narratives they have heard as a guide for how the event is likely to unfold. In this sense, narratives could be seen as functioning as templates or scripts for future events (e.g., Mazzocco, Green \& Brock, 2007; Schank \& Berman, 2002). This template-based account would certainly mesh well with the importance of resemblances in the influence process, as shown in the current data. However, there are potential alternative explanations (e.g., participants being unable to effectively process too many conflicting considerations). Future research can address this issue of mechanism more explicitly.

Finally, the current research addresses medical decisions made for another person, which is appropriate given that online health searches are often for another person, such as a family member (Fox, 2011). An important question is whether these same mechanisms work for selfchoices. Such cases fit into our conceptual framework (the judgment case is the self). However, self-relevance may make people more critical consumers of evidence (Petty \& Cacioppo, 1984), and so may eliminate the effects of distracting similarities. While experimental manipulations of similarity to the self may be more noisy (as participants will have unanticipated characteristics and experiences echoed in testimonials), these questions are open to empirical test.

In conclusion, the key message of the current studies is that the abundance of medical narratives available to people can have negative effects on their decision making. Even irrelevant, unimportant similarities to a narrative can influence people's decisions and lead them away from more relevant, important similarities to other testimonials.

\section{References}

Albarracín, D., \& Mitchell, A. L. (2004). The role of defensive confidence in preference for proattitudinal information: How believing that one is strong can sometimes be a defensive weakness. Personality and Social Psychology Bulletin, 30, 1565-1584. doi:10.1177/0146167204271180

Appel, M. \& Richter, T. (2010). Transportation and need for affect in narrative persuasion: A mediated moderation model. Media Psychology, 13, 101-135. doi:10.1080/15213261003799847 
Barden, J., \& Petty, R. E. (2008). The mere perception of elaboration creates attitude certainty: Exploring the thoughtfulness heuristic. Journal of Personality and Social Psychology, 95, 489509. doi:10.1037/a0012559

Cacioppo, J. T., Petty, R. E., \& Kao, C. F. (1984). The efficient assessment of need for cognition. Journal of Personality Assessment, 48, 306-307. doi:10.1207/s15327752jpa4803_13

Cohen, J., Cohen, P., West, S. G., \& Aiken, L. S. (2003). Applied multiple regression / correlational analysis for the behavioral sciences (3rd ed.). Mahwah, N.J: L. Erlbaum Associates.

Dal Cin, S., Zanna, M. P., \& Fong, G. T. (2004). Narrative persuasion and overcoming resistance. In E. S. Knowles \& J. Linn (Eds.), Resistance and persuasion (pp. 175-191). Mahwah, NJ: Erlbaum.

Eysenbach, G. (2008). Medicine 2.0: Social networking, collaboration, participation, apomediation and openness. Journal of Medical Internet Research, 10, 2-11. doi:10.2196/jmir.1030

Fletcher, G. O., Danilovics, P., Fernandez, G., Peterson, D., \& Reeder, G. D. (1986). Attributional complexity: An individual differences measure. Journal of Personality and Social Psychology, 51, 875-884. doi:10.1037/0022-3514.51.4.875

Fox, S. (2011). The social life of health information, 2011. Retrieved from the Pew Research Center website: http://www.pewinternet.org/Reports/2011/Social-Life-of-Health-Info.aspx

Green, M.C. (2004). Transportation into narrative worlds: The role of prior knowledge and perceived realism. Discourse Processes, 38(2), 247-266.

Green, M. C., \& Brock, T. C. (2000). The role of transportation in the persuasiveness of public narratives. Journal of Personality and Social Psychology, 79, 701-721. doi:10.1037/00223514.79.5.701

Grice, H. P. (1989). Studies in the way of words. Cambridge, MA: Harvard University Press.

Haugtvedt, C. P., \& Petty, R. E. (1992). Personality and persuasion: Need for cognition moderates the persistence and resistance of attitude changes. Journal of Personality and Social Psychology, 63, 308-319. doi:10.1037/0022-3514.63.2.308

Herrick, D. M. (2005). Consumer driven health care: The changing role of the patient (NCPA policy report no. 276). Retrieved from the National Center for Policy Analysis website: http://www.ncpa.org/pdfs/st276.pdf

Health 2.0. (2007, Sep 6). The Economist. Retrieved from http://www.economist.com/node/9719054

Kemmelmeier, M. (2004). Separating the wheat from the chaff: Does discriminating between diagnostic and non-diagnostic information eliminate the dilution effect? Journal of Behavioral Decision Making, 17, 231-241. doi:10.1002/bdm.473

Kreuter, M. W., Green, M. C., Cappella, J. N., Slater, M. D., Wise, M. E., Storey, D., ... Woolley, S. (2007). Narrative communication in cancer prevention and control: A framework to guide research and application. Annals of Behavioral Medicine, 33, 221-235. doi:10.1007/BF02879904

Mazzocco, P. J., Green, M. C., \& Brock, T. C. (2007). The effects of a prior story-bank on the processing of a related narrative. Media Psychology, 10, 64-90. doi:10.108/15213260701300980

Mazzocco, P. J., Green, M. C., Sasota, J. A., \& Jones, N. W. (2010). This story is not for everyone: Transportability and narrative persuasion. Social Psychological and Personality Science, 1, 361368. doi:10.1177/1948550610376600 
McLean, K. C., Pasupathi, M., \& Pals, J. L. (2007). Selves creating stories creating selves: A process model of self-development. Personality and Social Psychology Review, 11, 262-278. doi: $10.1177 / 1088868307301034$

Moyer-Gusé, E., \& Nabi, R. L. (2010). Explaining the effects of narrative in an entertainment television program: Overcoming resistance to persuasion. Human Communication Research, 36, 26-52. doi:10.1111/j.1468-2958.2009.01367.x

Petrocelli, J. V., Tormala, Z. L., \& Rucker, D. D. (2007). Unpacking attitude certainty: Attitude clarity and attitude correctness. Journal of Personality and Social Psychology, 92, 30-41. doi:10.1037/0022-3514.92.1.30

Petty, R. E., \& Cacioppo, J. T. (1984). The effects of involvement on responses to argument quantity and quality: Central and peripheral routes to persuasion. Journal of Personality and Social Psychology, 46, 69-81. doi:10.1037/0022-3514.46.1.69

Priester, J. R., \& Petty, R. E. (1996). The gradual threshold model of ambivalence: Relating the positive and negative bases of attitudes to subjective ambivalence. Journal of Personality and Social Psychology, 71, 431-449. doi:10.1037/0022-3514.71.3.431

Schank, R. C., \& Berman, T. R. (2002). The pervasive role of stories in knowledge and action. In M. C. Green, J. J. Strange, T. C. Brock (Eds.), Narrative impact: Social and cognitive foundations (pp. 287-313). Mahwah, NJ US: Lawrence Erlbaum Associates Publishers.

Strange, J. J., \& Leung, C. C. (1999). How anecdotal accounts in news and fiction can influence judgments of a social problem's urgency, causes, and cures. Personality and Social Psychology Bulletin, 25, 436-449. doi:10.1177/0146167299025004004

Tversky, A., \& Kahneman, D. (1974). Judgment under uncertainty: Heuristics and biases. Science, 185, 1124-1131. doi:10.1126/science.185.4157.1124

Winterbottom, A., Bekker, H. L., Conner, M., \& Mooney, A. (2008). Does narrative information bias individual's decision making? A systematic review. Social Science \& Medicine, 67, 2079-2088. doi:10.1016/j.socscimed.2008.09.037 
Distracted by Details | 18

\section{Appendix - Testimonials and judgment case}

\section{Sean Bryant}

Gender: Male Age: $29 \quad$ Ethnicity: Caucasian

I guess I'm a pretty normal guy. Certainly, there's no reason I can think of that I would be more at risk than anyone else for diseases. Well, I suppose I don't always think as much about my health as I should. I'm kind of focused on other people, you know? I mean, just look at my job - straight out of college, everyone else is dreaming of fame and riches, and I get a job working for local government, making sure people are getting the help and services they need. I still love it, all these years later. Anyhow, perhaps that means I don't always pay as much attention to what's going on with me as I should.

Looking back now, I realize I had been suffering on and off with the disease for a while, just mild stomach pains, nothing you would really notice. I always thought it was just indigestion from eating too fast! Anyhow, this one evening I got pains, like before, but then it just suddenly got a lot worse. It was like someone had kicked me right in the gut, or maybe stuck a knife into me. I couldn't help but collapse on the floor, it was that bad - must of looked kind of funny, me just suddenly sitting down like that! Anyway, I sat there for a few minutes, convinced I was dying, but the pain receded a bit and I could get to bed. Even then, though, it was so bad I could hardly sleep most of the night. After that, I figured I should get it checked out!

I felt a bit foolish going to the doctor, because by then I had convinced myself it was just bad indigestion. It's a good thing I steeled myself to go, though, because he sent me for some tests which clearly showed the ELD. When he explained that it could end up with me dying in an ICU I was pretty freaked out. I felt kind of numb, everything just seemed kind of grey and dull. I was restless all that evening, nothing could hold my interest or anything. I ended up getting up in the middle of the night to listen to Beethoven. I've loved his music since my mom used to play it when I was a kid. I always listen to it when I'm feeling stressed, but this time it couldn't help. It shows just how much the whole thing had got to me.

I remember it was about 5, 5:30 in the morning or something. There were just the first glimpses of light, the edges of the clouds were just showing in the dark. And I just felt this shift, a change in perspective. Instead of feeling bad about all the problems, all I could think about was the doctor telling me how lucky I was to have found out about it so early. You see, the earlier you catch it, the more effective corticosteroids will be at holding off the major symptoms. It's funny how you latch on to a piece of good news in a situation like that. I just saw how much worse things could have been.

I got started on the corticosteroids, and have been taking them since. In general, they've been great. I'm the main wage earner, and my family is dependent on me working, so it was really good that I didn't have to take too much time off. If I had to be stuck in a hospital for months, my job would really be on the line, and I don't know how we would get by if I got fired! Things aren't all great: I still get abdominal pains now and then, nothing as bad as before, and I have to be a little careful, making sure I don't drink too much and watching out for other infections. That's stuff you should be doing anyway, though, so it's no great hardship. In all, my experience has been really positive, and I feel really lucky to have come out of it so well. 


\section{Philip Alexander}

Gender: Male Age: $29 \quad$ Ethnicity: Caucasian

It's always hard to talk about yourself in things like this. What to say? Well, I guess if you asked my friends, they'd all say I'm a baseball fanatic! It seems superficial, but I guess that's one of my most defining features - I started playing as a kid, and I still play with friends now. I coach the local kids' team too - I love seeing them all so happy playing outside. I mean, I play other sports, but baseball has always been the one I came back to.

Actually, that is relevant to my first “real” experience of the ELD. When I started having stomach pains, I didn't really think twice about them. I mean, initially they seem like nothing important, just regular pains that could be caused by a million minor things. So, you just grit your teeth and get through them. But then, this one day I was out playing ball with my friends. The pains came on, and were just so much worse than anything I had felt before. Fortunately, I wasn't on the field at the time - that would have been really embarrassing! I got through the first wave, and then it got a bit better. It still hurt like hell, though - I had to leave the game and get my buddy to drive me back, because I wouldn't have been able to drive myself.

After that, I knew I had to see the doctor. I went in the next day, hoping it would be something fairly minor. Then I find out my liver is slowly dying! Finding out there was something so majorly wrong with my body was really jarring - it really makes you realize you are not immortal, you know? You build your life without thinking about dying, and then you find out that you're just a sack of organs.

I think it was made worse by the fact I've always been a pretty big, healthy guy - I must have a strong immune system or something, because I've never really suffered much even from small stuff like colds. However, it also made the decision to go for the amphates easier. They are more risky than the other treatments, but because I'm built like an ox, the doctors thought I would probably pull through with no problems. I went in just a few weeks after.

Going in for the treatment was scary, but it's the weeks after which are tough. You're holed up in the hospital, totally out of your routine. The doctors always told me this was when problems are most likely to arise, because the isolation and loneliness can be stressful, and that can really mess you up when you're trying to recover from a major procedure. I'm very lucky in that I have a really great group of friends. I never drifted too far out of touch with reality because they were always visiting me in the hospital, making sure I was OK, looking after me, you know? I had so much fruit I had to start giving it away! I also had a great set of nurses with a fantastic sense of humor. I've got this very fine blond hair, and so they always used to tease me about being an overgrown kid, sat in bed being waited on by them. They always called me 'the little prince', as if I was this spoiled little brat faking it to get out of school or something. It was great to be able to have a joke with them. It was a tough few months, no doubt about it, but it could have been a lot worse, and going through it has really made me appreciate normality. Like they say, every day is a bonus! Just to be able to get up, go about my day, it feels great. 


\section{Chris Russell}
Gender: Male
Age: 28
Ethnicity: Caucasian

It was pretty easy for me to tell I was sick. Looking back, I suppose I did ignore the early signs - just some mild on-and-off pains, that kind of thing. [At first, I figured it was stress, so I'd try and do things to relax. I remember I always used to go and dig out my favorite classical music records: Bach, Mozart, Brahms - music I used to love but hadn't listened to for years!] I've always been pretty tough and healthy in the past - I never really get sick that much. I don't know why - I guess I am just a naturally resilient kind of guy! Some people are like that - just naturally tough.] I just tried to shrug the pains off, carry on as normal. But the pains got more and more frequent, and more and more intense - so bad it even made me vomit pretty often. Even that I laughed off at first. [My girlfriend found it hysterical too - I've got blond hair and generally look kind of boyish, she said the contrast between that and all the retching just cracked her up! She said I looked like a hungover cherub!] Still, after it happened a few times in a single week, I guessed something was wrong, so I went to see the doctor. [As much as anything else, money's tight, and so I couldn't afford to keep taking the time off work. I mean, my boss was pretty understanding, but it's hard to keep things running when someone keeps disappearing on you - I'm afraid if I take too much time off, he'll have to fire me.I

When I went in, I was nervous, but made myself face up to what was happening. I mean, I knew there was something wrong, and although that was scary, I had to sort it out or it was just going to get worse. Because of that, I really appreciated that the doctor was very straight with me. He laid out the possible diagnoses up front, explained to me why he thought it was ELD, and got me in to do the confirmatory tests as soon as possible. He never tried to sugar coat what he was saying, or make out the risks were less than they were. I really liked that - I felt I could trust in what he was saying, and didn't have to decipher what he really meant. I mean, you always want to believe these things are less serious than they are, so it's good to have someone you trust to be the voice of reason.

When I got the diagnosis back, it did throw me a bit. [We did catch it pretty early, which was good, but it's still a major disorder. I mean, an early diagnosis helps with some of the treatments, which is great, but it's still a part of you dying off!] [I like being outside, playing sports - I've always played baseball, ever since I was a kid. It means a lot to me, and the prospect of not being able to do those kinds of things anymore really terrifies me.] [But then, thinking about it, I got a little perspective - I work for the local government, so I see people in the community dealing with far, far worse problems than I have.] [My friends have been really outstanding, though; they've done so much more than I could have expected in terms of talking things through and being supportive - it's so much easier to deal with these things when you don't feel alone.] So now I've got to decide which treatment to take, and I'm really not sure. I'm aware that each has its advantages and disadvantages, and I'm really not sure which one is going to be best for me.

Resemblance manipulation: Key

[Irrelevant similarity to Sean Bryant] [Relevant similarity to Sean Bryant]
[Irrelevant similarity to Philip Alexander] [Relevant similarity to Philip Alexander] 